\title{
The evolution of the diminishing role of extrapleural pneumonectomy in the surgical management of malignant pleural mesothelioma
}

This article was published in the following Dove Press journal:

OncoTargets and Therapy

25 November 2016

Number of times this article has been viewed

\author{
Abdel-Ghani Azzouqa' \\ James P Stevenson ${ }^{2}$ \\ 'Department of Hematology and \\ Oncology, Mayo Clinic, Jacksonville, \\ FL, ${ }^{2}$ Department of Hematology and \\ Oncology, Cleveland Clinic Taussig \\ Cancer Institute, Cleveland, OH, USA
}

\begin{abstract}
Malignant pleural mesothelioma is an uncommon and aggressive thoracic malignancy that is rarely curable, even when multimodality therapy is used. Systemic chemotherapy is the primary treatment for the majority of patients with this disease; however, surgical resection may benefit a subset of patients with early-stage disease. The surgical approach that offers the best outcomes remains an area of controversy, with data from retrospective comparisons being the only guide. Historically, extrapleural pneumonectomy (EPP) has been the standard procedure, carrying with it a cost of significant morbidity and impact on quality of life that has raised questions regarding its routine application. Over the past two decades as surgical techniques have been refined and survival data with EPP in large case series have been reported, the paradigm has evolved toward the use of lung-sparing pleural resections such as pleurectomy/ decortication $(\mathrm{P} / \mathrm{D})$ and extended $\mathrm{P} / \mathrm{D}$. The identification of patients who may benefit from EPP over pleurectomy has proven problematic, and the larger question regarding the impact of any type of surgical intervention on outcomes for pleural mesothelioma patients is still an area of investigation. Uniform treatment approaches have been difficult to develop due to the relatively small numbers of patients with this disease, the use of a staging system that does not readily identify those who may benefit from more aggressive therapy, and the institutional biases that have resulted from the growth of multimodality centers of excellence.
\end{abstract}

Keywords: mesothelioma, pneumonectomy, thoracic surgical procedure, multimodal treatment

\section{Introduction}

Malignant pleural mesothelioma (MPM) is a pleural mesothelial cancer that is aggressive in nature with a median survival of $<12$ months, a number that has shown little change in the past four decades, according to the results of a recent analysis of the Surveillance, Epidemiology, and End-Results (SEER) database. ${ }^{1}$ Asbestos exposure, typically in the workplace, has been well established as the major risk factor in the development of this malignancy, and the risk for the development of MPM among asbestos workers was at one time thought to be as high as $17 \%$ in those exposed at younger ages. ${ }^{2}$ The latency period between initial asbestos exposure and diagnosis is typically $>30$ years, which renders any effective screening effort nearly impossible. ${ }^{3}$ According to the World Health Organization (WHO) database, between the years 1994 and 2008, 92,253 deaths from MPM were reported in 83 countries with a mean age of 70 years and a 3.6:1 male to female ratio; $54 \%$ of reported deaths were in Europe and not surprisingly during the time frame studied, the reported cases were noted to shift to countries where workplace asbestos exposures have continued. ${ }^{4-6}$
Correspondence: James P Stevenson

Cleveland Clinic Taussig Cancer Institute, 9500 Euclid Avenue,

Cleveland, OH 44195, USA

$\mathrm{Tel}+\mathrm{I} 2166366888$

$\mathrm{Fax}+\mathrm{I} 2166362498$

Email stevenj5@ccf.org 
Nonoccupational exposure to asbestos (eg, in areas with asbestos-rich soil or inhalation of other fibrous silicates) can also contribute to an increased risk of MPM. ${ }^{7-9}$ Ionizing radiation (therapeutic or nontherapeutic) to upper body may be a risk factor for the subsequent development of MPM, again with a long latent period. ${ }^{10-12}$ Oncogenic viral infections, such as Simian virus 40 (SV40) infections, have been implicated in the etiology of MPM, although a clear relationship has yet to be established. ${ }^{13-16}$ How can clinicians set the bar to measure the contribution of any therapies to improvement in outcomes for MPM? The natural history of untreated MPM was elegantly described by Ruffie et al, ${ }^{17}$ in a retrospective study of 332 Canadian patients from 1965 to 1984; the median survival was only 9 months for the entire group, and for 176 patients who received no treatment, the median survival was 7 months. The clinical and laboratory information was supplemented by autopsy results in 92 patients, and while lymphatic and hematogenous metastases were detected in $50 \%$, local progression of the disease was felt to be the main contributing factor for mortality.

Systemic chemotherapy in the absence of surgical resection has been shown to improve survival in MPM. Results from the MS01 trial showed a nonsignificant improvement in median survival with single-agent vinorelbine chemotherapy over symptom care alone (9.5 vs 7.5 months, $P=0.08){ }^{18}$ Vogelzang et $\mathrm{al}^{19}$ demonstrated the efficacy of cisplatin plus pemetrexed in a phase III clinical trial (EMPHACIS). A total of 456 patients were randomized to receive either pemetrexed/ cisplatin or cisplatin alone. Compared to single agent cisplatin, patients in the combination chemotherapy arm had improved response rate (RR, $41.3 \%$ vs $16.7 \%, P<0.0001$ ), time to progression (5.7 vs 3.9 months, $P=0.001$ ), and overall survival (OS) (12.1 vs 9.3 months, $P=0.020$ ). After 117 patients had enrolled, folic acid and vitamin B12 were added, resulting in a significant reduction in toxicities in the pemetrexed/ cisplatin arm without adversely affecting survival. Subsequent analyses showed that the pemetrexed/carboplatin combination produces similar response, time to progression, and 1-year survival rates to pemetrexed/cisplatin. ${ }^{20}$ Most recently, the combination of pemetrexed, cisplatin, and bevacizumab was shown to produce a median survival of 18.8 months in a French Intergroup randomized trial of 448 patients. ${ }^{21}$ Accordingly, the current expectation is that platinum/pemetrexedbased chemotherapy can produce median survival rates of 12-18 months in the absence of surgical resection.

\section{Surgery for MPM}

The surgical management of MPM remains a controversial subject, particularly as larger analyses confirm that even the most aggressive surgical approaches rarely result in cure or long-term survival. The evidence to date still has major deficiencies, due to the lack of prospective comparative analyses. Despite this, surgery continues to play a major role in the management of MPM, with the achievement of macroscopic resection of tumor now recognized as the goal. The International Association for the Study of Lung Cancer (IASLC) has currently defined the procedures that are typically used for gross tumor reduction, such as extrapleural pneumonectomy (EPP), pleurectomy/decortication (P/D), and extended pleurectomy/decortication (e-P/D; Table 1). ${ }^{22,23}$

\section{Historical perspective}

\section{Extrapleural pneumonectomy}

EPP entails en bloc resection of the visceral and parietal pleura, pericardium, ipsilateral hemidiaphragm, and lung. This is the most extensive procedure in the treatment of MPM and has the highest rates of perioperative mortality and morbidity based on the available data. In 1976, Butchart et $\mathrm{al}^{24}$ published an initial experience with 29 patients with MPM and they reported a hospital mortality rate of $31 \%$ with a median survival of $<6$ months. Two patients were noted to survive $>3$ years. They concluded that pleuropneumonectomy does not affect the course of the disease in mixed epithelial and sarcomatoid histological types; however, stage I patients with pure epithelial type carried a better prognosis, particularly an epithelioid subtype with mucoid stroma. Thus, the earliest reported experience with EPP in MPM suggested that only subsets of patients may benefit from major resection.

In 1991, the Lung Cancer Study Group (LCSG) evaluated 83 surgical patients from 1985 to 1988 and found that EPP could be completed in only $20(24 \%)$, with a mortality rate of $15 \% .{ }^{25}$ The authors concluded that only a small proportion of patients with MPM were candidates for EPP and that the procedure did not seem to improve overall survival compared with more conservative management.

Table I IASLC definitions of surgical procedures for malignant pleural mesothelioma

\begin{tabular}{ll}
\hline $\begin{array}{l}\text { Extrapleural } \\
\text { pneumonectomy (EPP) }\end{array}$ & $\begin{array}{l}\text { En bloc resection of the visceral and } \\
\text { parietal pleura, pericardium, ipsilateral } \\
\text { hemidiaphragm, and lung } \\
\text { Resection of the parietal and visceral } \\
\text { Pleurectomy/ }\end{array}$ \\
plecortication (P/D) & $\begin{array}{l}\text { removing diaphragm or pericardium } \\
\text { The same as P/D with resection of the } \\
\text { Extended P/D (e-P/D) }\end{array}$ \\
Partial pleurectomy & $\begin{array}{l}\text { Partial removal of the parietal and/or visceral } \\
\text { pleura for diagnostic or palliative intentions }\end{array}$ \\
\hline
\end{tabular}

Note: Data from Rice et al. ${ }^{22}$

Abbreviation: IASLC, International Association for the Study of Lung Cancer. 
Clearly, the early experience with EPP as definitive therapy for MPM was dismal and did not justify broad application in this fashion. Adding to the often heated discussion regarding the value of EPP for MPM was the report of a feasibility study performed by the MARS trial group in the UK, designed to test the randomized inclusion of EPP vs no EPP as part of multimodality therapy. ${ }^{26} \mathrm{~A}$ total of 112 eligible patients recruited from 11 collaborating centers entered the first registration to receive platinum-based chemotherapy. Fifty patients (45\%) were subsequently randomized to EPP (24/50) or best nonsurgical care (26/50). In all, 67\% (16 out of 24 ) in the surgery arm completed EPP satisfactorily. ${ }^{27}$ Median survival (after induction chemotherapy) was 14.4 months for the EPP group and 19.5 months for the non-EPP group. Median quality-of-life scores were lower in the EPP group, although not statistically significant. The sample size was insufficient to analyze outcome as the primary end points, but the results have prompted debate that EPP offers no survival benefit and possibly harms patients within the multimodality treatment setting.

\section{Pleurectomy}

The morbidity associated with EPP stands in contrast to alternative cytoreductive lung-sparing procedures such as $\mathrm{P} / \mathrm{D}$ and e-P/D, and pleurectomy is potentially applicable to a larger group of MPM patients. As currently defined, the aim of both procedures is the removal of all macroscopic tumors and, in the case of e-P/D, resection of the ipsilateral pericardium and diaphragm.

Early reports of pleurectomy for MPM typically included the use of other therapies such as radiotherapy and chemotherapy in the adjuvant setting. ${ }^{28}$ Wanebo et a ${ }^{29}$ at Memorial Hospital reported a median survival of 21 months in patients with epithelial histology who underwent pleural resection with or without radiation, with three patients surviving $>5$ years. The median survival improved to 30 months in those that received chemotherapy.
Law et $\mathrm{a}^{30}$ at the Brompton and Royal Marsden Hospitals described their experience from 1971 to 1980: there was a median survival of 20 months with $\mathrm{P} / \mathrm{D}$, including three patients who survived $>4$ years. Contrasting this group were 64 patients who received no therapy other than symptom control, showing a median survival of 18 months with seven $(11 \%)$ surviving $\geq 4$ years. Differences in survival by histological subtype were not found in these groups.

The role of pleurectomy in MPM treatment has been examined in other recent reports. In a systematic review of 11 retrospective studies, Zahid et $a l^{31}$ concluded that these procedures may lead to superior survival rates but at the expense of higher morbidity when compared to palliative treatment. Radical P/D achieved a higher median survival than best supportive care (14.5 vs 4.5 months) and nonradical decortication (15.3 vs 7.1 months, $P<0.001$ ) but had a complication rate of $30 \%$ and an operative mortality rate of $9.1 \%$. In a separate large review of 1,270 patients undergoing lung-sparing surgical procedures for MPM, Teh et $\mathrm{al}^{32}$ reported 1 -year postoperative survival rates of $51 \%$ and $9 \%$ at 5 years.

\section{Modern comparative surgical reports}

Flores et $\mathrm{al}^{33}$ published a landmark retrospective case series in 2008 describing 663 consecutive patients undergoing EPP or P/D from 1990 to 2006 at three US academic surgical centers and found improved median survival for P/D vs EPP (16 vs 12 months). This was statistically significant $(P<0.001)$ after controlling for gender, histology, stage, and receipt of multimodality therapy. Compared to EPP, P/D was associated with lower operative mortality ( $3 \%$ vs $7 \%$ ) and lower distant (35\% vs $66 \%$ ) but not local ( $65 \%$ vs $33 \%$ ) recurrence rates (Table 2). This publication led to renewed examination of surgical procedures among thoracic surgeons specializing in MPM treatment, and multiple reviews and institutional reports/experiences have followed.

Table 2 Comparative reports of EPP and P/D in malignant pleural mesothelioma

\begin{tabular}{|c|c|c|c|}
\hline Study & $\mathbf{N}$ & Notable outcomes & Comments \\
\hline Flores et $\mathrm{al}^{33}$ & 663 & $\begin{array}{l}\text { P/D associated with improved median survival } \\
\text { and operative mortality vs EPP }\end{array}$ & $\begin{array}{l}\text { Limited by selection bias at three } \\
\text { institutions }\end{array}$ \\
\hline Lang-Lazdunski et a ${ }^{35}$ & 75 & $\begin{array}{l}\text { Median OS } 23 \text { months for e-P/D vs } 12.8 \text { months } \\
\text { for EPP. No perioperative mortality with e-P/D }\end{array}$ & Prospective single-institution experience \\
\hline IASLC $^{34}$ & 3,101 & $\begin{array}{l}\text { EPP associated with improved survival vs P/D in } \\
\text { stage I patients only }\end{array}$ & $\begin{array}{l}\text { Selection bias, data limitations, and small } \\
\text { number of stage I patients to compare }\end{array}$ \\
\hline Cao et $\mathrm{al}^{36}$ & $\mathrm{I}, \mathrm{I} 45$ & $\begin{array}{l}\text { Lower perioperative mortality and morbidity with } \\
\text { e-P/D. Unable to compare survival outcomes }\end{array}$ & Meta-analysis \\
\hline Taioli et a $\left.\right|^{37}$ & 2,903 & $\begin{array}{l}\text { 2.5-fold lower 30-day mortality with P/D; similar } \\
\text { 2-year survival for P/D and EPP }\end{array}$ & $\begin{array}{l}\text { Meta-analysis; survival analysis limited } \\
\text { by data heterogeneity }\end{array}$ \\
\hline
\end{tabular}

Abbreviations: IASLC, International Association for the Study of Lung Cancer; EPP, extrapleural pneumonectomy; e-P/D, extended pleurectomy/decortication; P/D, pleurectomy/decortication. 
The 2012 publication of the IASLC mesothelioma database of 3,101 patients from four continents showed that among 1,489 MPM patients who underwent surgery with curative intent, patients with stage I disease (total 132 patients) resected by EPP had a median survival of 40 months compared to 23 months for $\mathrm{P} / \mathrm{D}$, with no difference in survival at later stages. ${ }^{34}$ Patients undergoing any type of curative intent surgery had superior survival with multimodality therapy when compared to surgery alone (20 vs 11 months). The small number of stage I patients with adequate data made it difficult to draw strong conclusions regarding the differences in survival by procedure, and the authors acknowledged the potential contribution of institutional selection bias to the results.

Lang-Lazdunski et a ${ }^{35}$ also published in 2012 a comparison of their prospective institutional experience with 76 patients who underwent e-P/D or EPP as part of multimodality therapy. Of 22 patients who received neoadjuvant chemotherapy and subsequent EPP, 17 received adjuvant thoracic radiotherapy; 54 patients underwent e-P/D and intraoperative hyperthermic pleural lavage and then received prophylactic radiotherapy to chest tube sites and adjuvant chemotherapy. Both groups were not different in age, gender, histology, and nodal status. The 30 -day mortality was $4.5 \%$ for the EPP group and zero for the e-P/D group; only $68 \%$ of the EPP group completed full multimodality treatment compared to $100 \%$ of the e-P/D patients. Survival was superior in the e-P/D group with median OS of 23 months vs 12.8 months for the EPP group. The authors concluded e-P/D should be the standard surgical procedure for MPM patients as part of multimodality therapy.

The results of two published meta-analyses were quite similar in that the authors concluded that e-P/D and P/D were associated with significantly lower perioperative morbidity and mortality than EPP. ${ }^{36,37}$ While survival analyses were limited by data insufficiency and heterogeneity, Cao et $\mathrm{al}^{36}$ reported a longer overall median survival range of 13-29 months with e-P/D compared to 12-22 months for EPP, and Taioli et $\mathrm{al}^{37}$ found no significant difference in 2-year mortality ( $25 \%$ for P/D vs $23.8 \%$ for EPP, $P=0.08$ ). These results confirm that e-P/D and $\mathrm{P} / \mathrm{D}$ produce superior perioperative outcomes than EPP, with no clear differences in survival.

\section{Importance of multimodality therapy}

A common conclusion in the numerous surgical reports and reviews described here and elsewhere is that multimodality therapy produces better outcomes in MPM, and platinumbased chemotherapy, typically with an antifolate such as pemetrexed, should be considered a standard component. Hemithoracic radiation has historically been included in the treatment of MPM after EPP, yet full completion of a trimodality approach can prove difficult due to factors such as disease progression and treatment-induced morbidity/ mortality. ${ }^{38}$ Notably, an important recent randomized trial of hemithoracic radiation vs no radiation following neoadjuvant chemotherapy and EPP showed no differences in overall survival (19.3 vs 20.8 months).$^{39}$ Of note is that only 54 of 151 patients could be randomized, underscoring the difficulty in completing a controlled study of trimodality therapy in MPM. The authors concluded that adjuvant hemithoracic radiotherapy should not be routinely performed after EPP and that alternative treatment algorithms were needed in the multimodality approach to MPM.

One such unique approach was described by de Perrot et $\mathrm{al}^{40}$ at the Princess Margaret Cancer Center in Toronto. Patients with clinical stage T1-3N0M0 MPM received 25 Gy of hemithoracic intensity-modulated radiotherapy in five fractions followed by EPP 1 week later. Pathologic stage III/IV disease was noted in 24/25 patients treated in this trial, and 3 -year survival was $84 \%$ for patients with epithelial histology. Adjuvant chemotherapy for three to six cycles was administered to only five of 13 patients with pathologic $\mathrm{N} 2$ disease; the authors did not state the reasons for the low receipt of planned postoperative chemotherapy. Grade $3-5$ postsurgical complications occurred in $52 \%$ of patients, and there was no 30 -day perioperative mortality. One patient expired 88 days postoperatively due to empyema that was felt to be treatment related. The authors concluded that this multimodality approach was safe and promising but recognized the difficulty in completing a larger trial because of the shift from performing EPP at most centers with expertise in MPM. Wider applicability of this approach therefore seems unlikely.

Intensity-modulated pleural radiation therapy (IMPRINT) is a novel conformal radiotherapy technique to target pleural surfaces while limiting lung exposure. An early report of experience with IMPRINT at two centers was recently published. ${ }^{41}$ Four cycles of pemetrexed and cisplatin or carboplatin chemotherapy were initially administered to all patients; IMPRINT followed the chemotherapy in patients felt not to be candidates for surgery (11 patients) or was administered within 8 weeks following e-P/D or P/D (16 patients). The median progression-free survival (PFS) and OS for the 27 evaluable patients were 12.5 and 23.7 months, respectively, and 2-year survival was $59 \%$ in patients undergoing resection. Local failure occurred in $59 \%$ of patients. The authors deemed IMPRINT to be a safe technique with no grade 4 or 5 radiation-related toxicity, suggesting that it 
Table 3 Factors found to significantly impact survival after surgery in malignant pleural mesothelioma as determined by the analysis of the IASLC database

\begin{tabular}{lll}
\hline Risk factors & Favorable & Unfavorable \\
\hline Histology & Epithelial & Other types \\
Nodal status & No & NI/N2 \\
T stage & TI & T3/T4 \\
Gender & Female & Male \\
Age, years & $<50$ & $>65$ \\
Surgical intent & Curative & Palliative
\end{tabular}

Note: Data from Rusch et al..$^{34}$

Abbreviation: IASLC, International Association for the Study of Lung Cancer.

could be a favorable addition to lung-sparing multimodality treatment; a multicenter study of IMPRINT following P/D and adjuvant chemotherapy is planned. Due to the expertise and experience required to safely deliver IMPRINT, this technique may also prove to have limited applicability to a handful of treatment sites.

\section{Prognostic factors and patient selection}

The goal of the 2012 IASLC analysis was not to compare surgical approaches to MPM but to suggest a revised staging system for this disease, in recognition of the limitations of the prior (7th Edition) AJCC TNM staging system. ${ }^{34}$ Multivariate analyses showed the following risk factors (Table 3) to significantly impact survival in patients undergoing surgery:

1. T stage: most apparent in patients undergoing surgery with curative intent, hazard ratio (HR) for T2 vs T1 was 1.16 and HR for T4 vs T1 1.66.

2. Nodal status: HR for $\mathrm{N} 1$ vs $\mathrm{N} 0$ was 1.26 and N2 vs N0 1.4.

3. Tumor histology: HR for epithelial having better outcomes, other histology vs epithelial was 1.70 .

4. Gender: HR for male vs female was 1.25.

5. Age: HR for $>65$ vs $<50$ years was 1.24 .

6. Surgical intent: HR for palliative vs curative intent surgery was 1.77 .

From these data, it is clear that such factors are critical in the determination as to whether an individual patient may benefit from surgical resection where removal of macroscopic tumor is the goal.

\section{Conclusion and future directions}

Surgical resection with the goal of removal of macroscopic tumor can be considered in only a small percentage of patients who present with MPM. That distant and/or local recurrences are certain after aggressive surgical approaches unfortunately emphasizes that these procedures are not curative. Therefore, the demonstration of a meaningful impact of surgery in the form of prolongation of overall survival without significant morbidity or detrimental impact on quality of life is needed but is currently lacking. Repeated analyses of historical datasets do not show a benefit to EPP over e-P/D or P/D, and this procedure should one day also be rendered of historical interest only, with rare exceptions. Multidisciplinary management and treatment planning at centers that are experienced in MPM management should be the norm for patients with this disease, given the relatively small number of cases that present on a yearly basis. Institutional bias and practice will continue to have a major influence on the surgical approaches used, and the selection that occurs in the accrual and reporting of small multimodality trials makes it difficult to incorporate neoadjuvant or adjuvant therapies with confidence. However, one current randomized trial should provide helpful data in the future. The MARS investigators have followed their initial feasibility trial of EPP with the MARS2 trial, of similar design, but patients are randomized to chemotherapy alone or chemotherapy + e-P/D. Feasibility of randomization of 50 patients in the allotted 2-year period is the primary end point, with survival and quality of life being measured as secondary end points.

\section{Disclosure}

James P Stevenson: research funding to Cleveland Clinic from Verastem, Bayer, and Merck. The other author reports no conflicts of interest in this work.

\section{References}

1. Taioli E, Wolf AS, Camacho-Rivera M, et al. Determinants of survival in malignant pleural mesothelioma: a surveillance, epidemiology, and end results (SEER) study of 14,228 patients. PLoS One. 2015;10(12): e0145039.

2. Selikoff IJ, Hammond EC, Seidman H. Latency of asbestos disease among insulation workers in the United States and Canada. Cancer. 1980; 46(12):2736-2740.

3. Peto J, Seidman H, Selikoff IJ. Mesothelioma mortality in asbestos workers: implications for models of carcinogenesis and risk assessment Br J Cancer. 1982;45(1):124-135.

4. Delgermaa V, Takahashi K, Park EK, Le GV, Hara T, Sorahan T. Global mesothelioma deaths reported to the World Health Organization between 1994 and 2008. Bull World Health Organ. 2011;89(10):724A-724C.

5. Robinson BW, Musk AW, Lake RA. Malignant mesothelioma. Lancet. 2005;366(9483):397-408.

6. Peto J, Decarli A, La Vecchia C, Levi F, Negri E. The European mesothelioma epidemic. Br J Cancer. 1999;79(3-4):666-672.

7. Metintas S, Metintas M, Ucgun I, Oner U. Malignant mesothelioma due to environmental exposure to asbestos - follow-up of a Turkish cohort living in a rural area. Chest. 2002;122(6):2224-2229.

8. Pan XL, Day HW, Wang W, Beckett LA, Schenker MB. Residential proximity to naturally occurring asbestos and mesothelioma risk in California. Am J Respir Crit Care Med. 2005;172(8):1019-1025.

9. Gulmez I, Kart L, Buyukoglan H, Er O, Balkanli S, Ozesmi M. Evaluation of malignant mesothelioma in central Anatolia: a study of 67 cases. Can Respir J. 2004;11(4):287-290.

10. Tward JD, Wendland MM, Shrieve DC, Szabo A, Gaffney DK. The risk of secondary malignancies over 30 years after the treatment of nonHodgkin lymphoma. Cancer. 2006;107(1):108-115. 
11. Teta MJ, Lau E, Sceurman BK, Wagner ME. Therapeutic radiation for lymphoma - risk of malignant mesothelioma. Cancer. 2007;109(7): $1432-1438$.

12. Gibb H, Fulcher K, Nagarajan S, et al. Analyses of radiation and mesothelioma in the US Transuranium and Uranium Registries. Am J Public Health. 2013;103(4):710-716.

13. Comar M, Zanotta N, Pesel G, et al. Asbestos and SV40 in malignant pleural mesothelioma from a hyperendemic area of north-eastern Italy. Tumori. 2012;98(2):210-214.

14. Cristaudo A, Foddis R, Vivaldi A, et al. SV40 enhances the risk of malignant mesothelioma among people exposed to asbestos: a molecular epidemiologic case-control study. Cancer Res. 2005;65(8):3049-3052.

15. Lundstig A, Dejmek A, Eklund C, Filinic I, Dillner J. No detection of SV40 DNA in mesothelioma tissues from a high incidence area in Sweden. Anticancer Res. 2007;27(6B):4159-4161.

16. Manfredi JJ, Dong J, Liu WJ, et al. Evidence against a role for SV40 in human mesothelioma. Cancer Res. 2005;65(7):2602-2609.

17. Ruffie P, Feld R, Minkin S, et al. Diffuse malignant mesothelioma of the pleura in Ontario and Quebec: a retrospective study of 332 patients. J Clin Oncol. 1989;7(8):1157-1168.

18. Muers MF, Stephens RJ, Fisher P, et al; MS01 Trial Management Group. Active symptom control with or without chemotherapy in the treatment of patients with malignant pleural mesothelioma (MS01): a multicentre randomised trial. Lancet. 2008;371(9625):1685-1694.

19. Vogelzang NJ, Rusthoven JJ, Symanowski J, et al. Phase III study of pemetrexed in combination with cisplatin versus cisplatin alone in patients with malignant pleural mesothelioma. J Clin Oncol. 2003; 21(14):2636-2644.

20. Santoro A, O'Brien ME, Stahel RA, et al. Pemetrexed plus cisplatin or pemetrexed plus carboplatin for chemonaïve patients with malignant pleural mesothelioma: results of the International Expanded Access Program. J Thorac Oncol. 2008;3(7):756-763.

21. Zalcman G, Mazieres J, Margery J, et al; French Cooperative Thoracic Intergroup (IFCT). Bevacizumab for newly diagnosed pleural mesothelioma in the Mesothelioma Avastin Cisplatin Pemetrexed Study (MAPS): a randomised, controlled, open-label, phase 3 trial. Lancet. 2016;387(10026):1405-1414.

22. Rice D, Rusch V, Pass H, et al; International Association for the Study of Lung Cancer International Staging Committee and the International Mesothelioma Interest Group. Recommendations for uniform definitions of surgical techniques for malignant pleural mesothelioma: a consensus report of the international association for the study of lung cancer international staging committee and the international mesothelioma interest group. J Thorac Oncol. 2011;6(8):1304-1312.

23. Rice D. Standardizing surgical treatment in malignant pleural mesothelioma. Ann Cardiothorac Surg. 2012;1(4):497-501.

24. Butchart EG, Ashcroft T, Barnsley WC, Holden MP. Pleuropneumonectomy in the management of diffuse malignant mesothelioma of the pleura. Experience with 29 patients. Thorax. 1976;31(1):15-24.

25. Rusch VW, Piantadosi S, Holmes EC. The role of extrapleural pneumonectomy in malignant pleural mesothelioma. A Lung Cancer Study Group trial. J Thorac Cardiovasc Surg. 1991;102(1):1-9.

26. Treasure T, Waller D, Tan C, et al. The Mesothelioma and Radical surgery randomized controlled trial: the Mars feasibility study. J Thorac Oncol. 2009;4(10):1254-1258.

OncoTargets and Therapy

\section{Publish your work in this journal}

OncoTargets and Therapy is an international, peer-reviewed, open access journal focusing on the pathological basis of all cancers, potential targets for therapy and treatment protocols employed to improve the management of cancer patients. The journal also focuses on the impact of management programs and new therapeutic agents and protocols on
27. Treasure T, Lang-Lazdunski L, Waller D, et al; MARS trialists. Extrapleural pneumonectomy versus no extra-pleural pneumonectomy for patients with malignant pleural mesothelioma: clinical outcomes of the Mesothelioma and Radical Surgery (MARS) randomised feasibility study. Lancet Oncol. 2011;12(8):763-772.

28. Achatzy R, Beba W, Ritschler R, et al. The diagnosis, therapy and prognosis of diffuse malignant mesothelioma. Eur J Cardiothorac Surg. 1989;3(5):445-447.

29. Wanebo HJ, Martini N, Melamed MR, Hilaris B, Beattie EJ Jr. Pleural mesothelioma. Cancer. 1976;38(6):2481-2488.

30. Law MR, Gregor A, Hodson ME, Bloom HJ, Turner-Warwick M. Malignant mesothelioma of the pleura: a study of 52 treated and 64 untreated patients. Thorax. 1984;39(4):255-259.

31. Zahid I, Sharif S, Routledge T, Scarci M. Is pleurectomy and decortication superior to palliative care in the treatment of malignant pleural mesothelioma? Interact Cardiovasc Thorac Surg. 2011;12(5):812-817.

32. Teh E, Fiorentino F, Tan C, Treasure T. A systematic review of lungsparing extirpative surgery for pleural mesothelioma. JR Soc Med. 2011; 104(2):69-80.

33. Flores RM, Pass HI, Seshan VE, et al. Extrapleural pneumonectomy versus pleurectomy/decortication in the surgical management of malignant pleural mesothelioma: results in 663 patients. J Thorac Cardiovasc Surg. 2008;135(3):620-626.

34. Rusch VW, Giroux D, Kennedy C, et al; IASLC Staging Committee. Initial analysis of the international association for the study of lung cancer mesothelioma database. J Thorac Oncol. 2012;7(11):1631-1639.

35. Lang-Lazdunski L, Bille A, Lal R, et al. Pleurectomy/decortication is superior to extrapleural pneumonectomy in the multimodality management of patients with malignant pleural mesothelioma. J Thorac Oncol. 2012;7(4):737-743.

36. Cao C, Tian D, Park J, Allan J, Pataky KA, Yan TD. A systematic review and meta-analysis of surgical treatments for malignant pleural mesothelioma. Lung Cancer. 2014;83(2):240-245.

37. Taioli E, Wolf AS, Flores RM. Meta-analysis of survival after pleurectomy decortication versus extrapleural pneumonectomy in mesothelioma. Ann Thorac Surg. 2015;99(2):472-480.

38. Krug LM, Pass HI, Rusch VW, et al. Multicenter phase II trial of neoadjuvant pemetrexed plus cisplatin followed by extrapleural pneumonectomy and radiation for malignant pleural mesothelioma. $J$ Clin Oncol. 2009;27(18):3007-3013.

39. Stahel RA, Riesterer O, Xyrafas A, et al. Neoadjuvant chemotherapy and extrapleural pneumonectomy of malignant pleural mesothelioma with or without hemithoracic radiotherapy (SAKK 17/04): a randomised, international, multicentre phase 2 trial. Lancet Oncol. 2015;16(16): $1651-1658$.

40. de Perrot M, Feld R, Leighl NB, et al. Accelerated hemithoracic radiation followed by extrapleural pneumonectomy for malignant pleural mesothelioma. J Thorac Cardiovasc Surg. 2016;151(2):468-473.

41. Rimner A, Zauderer MG, Gomez DR, et al. Phase II study of hemithoracic intensity-modulated pleural radiation therapy (IMPRINT) as part of lung-sparing multimodality therapy in patients with malignant pleural mesothelioma. J Clin Oncol. 2016;34(23):2761-2768.

patient perspectives such as quality of life, adherence and satisfaction The manuscript management system is completely online and includes a very quick and fair peer-review system, which is all easy to use. Visit http://www.dovepress.com/testimonials.php to read real quotes from published authors. 